\title{
A ESCOLHA NA "POSIÇÃO ORIGINAL" DE JOHN RAWLS: O IDEALISMO DE UM UTILITARISTA CRÍTICO DO UTILITARISMO
}

\author{
Fernando Cézar Lopes Cassionato ${ }^{1}$ \\ Daniela Menengoti Gonçalves Ribeiro ${ }^{2}$
}

\begin{abstract}
RESUMO: John Bordley Rawls, em sua obra "Uma Teoria da Justiça", visa encontrar uma base comum de justificação do justo, com endosso de uma pluralidade de doutrinas. Neste trabalho serão analisados os princípios de sua teoria, os fundamentos de sua argumentação, e os argumentos favoráveis à defesa do princípio da diferença. Ao final serão feitas reflexões acerca da teoria de John Rawls: suas falhas ao não compensar as desigualdades naturais (falha reconhecida pelo autor), e a consequência de certas escolhas subsidiarem injustamente outras. Será utilizado o método de abordagem dedutivo e a pesquisa bibliográfica como procedimento.
\end{abstract}

PALAVRAS-CHAVE: Justificação do justo. Consenso sobreposto. Posição original. Princípios de justiça. Princípio da diferença. Críticas.

\section{THE CHOICE IN THE “ORIGINAL POSICION” OF THE JOHN RAWLS: THE IDEALISM OF A CRITICAL UTILITARIAN OF UTILIZARIANISM}

\footnotetext{
${ }^{1}$ Graduado em Direito pela Associação Educacional Toledo de Presidente Prudente/SP (2004), especialista em Direito Civil e Direito Processual Civil pela mesma Instituição de Ensino Superior (2006-2007), especialista em Direito Registral e Notarial pela Faculdade Fortium, FF, Brasil (2010-2011), especialista em Direito Imobiliário pela Universidade Gama Filho, UGF, Brasil (2012-2013). Mestrando na Unicesumar em Ciências Jurídicas com área de concentração em Direitos da Personalidade e aluno regularmente inscrito no curso intensivo válido para Doutorado da Universidade de Buenos Aires-ARG (UBA-ARG). Atualmente é oficial/tabelião no OFICIAL DE REGISTRO CIVIL DAS PESSOAS NATURAIS E TABELIONATO DE NOTAS DE AVANHANDAVA/SP, com experiência profissional na área Notarial e Registral. *Endereço postal: Rua Djalma Dutra, 740, Apto 93, Vila Ocidental, Presidente Prudente/SP, CEP 19015-040. *E-mail: fernandocassionato@ yahoo.com.br.

${ }^{2}$ Professora do Programa de Mestrado em Ciências Jurídicas e da graduação em Direito do Centro Universitário de Maringá (UNICESUMAR). Coordenadora/Líder dos Grupos de Pesquisa (CNPq): Instrumentos jurisdicionais de efetivação dos direitos da personalidade e Coordenadora/Líder do Grupos de Pesquisa (CNPq): Internacionalização do direito: dilemas constitucionais e internacionais contemporâneos. Pesquisadora do Instituto Cesumar de Ciência, Tecnologia e Inovação (ICETI). Doutora em Direito-Relações Econômicas Internacionais pela Pontifícia Universidade Católica de São Paulo (PUC/SP) com período de pesquisa (doutorado sanduíche) na Université Paris 1 - Panthéon-Sorbonne, França. Mestre em Direito-Relações Internacionais, pela Universidade Federal de Santa Catarina (UFSC), com período de pesquisa no Mestrado em Integrazione Europea da Università Degli Studi Padova, Itália. Bolsista CNPq no mestrado e no doutorado. Especialista em Comercio Internacional y Inversiones, pela Universidad de Buenos Aires (UBA), Argentina. Especialista em Direito e Negócios Internacionais pela Universidade Federal de Santa Catarina (USFC). Aperfeiçoamento em Marchés Internacionaux pela École Supérieure d'Agriculture d'Angers, França. Bacharel em Direito pela Unicesumar. Advogada. Dentre as linhas de pesquisa estão: Direito Internacional (Público e Privado), Direitos Humanos, Desenvolvimento Humano e Econômico. Colaboradora do blog: pretextointernacional.blogspot.com. * Endereço postal: Rua Antônio Vicentini, 541, jardim Novo Horizonte, Marialva, Paraná, Cep: 86990000. *E-mail: daniela.ribeiro@unicesumar.edu.br.
} 
ABSTRACT: John Bordley Rawls, in your book "A theory of justice", purpose find a common base of justification of just, whit endorsement of a doctrines plurality. In this work will be analyze the theory's principles, the fundaments of yours argumentation, and the favorable arguments to the defense of difference principle. In the end will be same reflextions about of John Rawls's theory, and the consequences subsidiaries unfairly others. Will be used the method of deductive approach and bibliographic research as procedure.

KEY-WORDS: Justification of just. Superimposed consensus. Original position. The justice principles. Difference principle. Reviews.

\section{INTRODUÇÃO}

A injustiça sempre foi um grande problema social a ser resolvido por aqueles que objetivam o bem geral de um povo. A isso chama-se de "problema de realização da justiça".

No processo que envolve essa busca por justiça, John BordleyRawls, começou a desenvolver em 1964/1965, anos da primeira versão preliminar, uma teoria da justiça fundamentada em princípios com a finalidade de encontrar uma base comum de justificação do justo, com endosso de uma pluralidade de doutrinas.

Crê-se que John Rawls desenvolveu interesse por questões sociais devido ao envolvimento de sua mãe com o movimento feminista em busca do direito ao voto para as mulheres (foi ela por algum tempo presidente da Liga para o Voto Feminino de Baltimore ${ }^{3}$ ), bem como por influência de sua própria realidade social, vivida em sua cidade natal, Baltimore, onde a população negra vivia em condições totalmente diferentes e inferiores à população branca.

Com uma noção claramente liberal, mas com preocupações igualitárias, John Rawls procurou argumentar em favor da escolha de um mundo mais igualitário porque nesse mundo a pessoa menos favorecida, considerada aquele que tem menos bens sociais primários, fica melhor em termos de distribuição desses mesmos bens.

Nesse viés, destacar-se-á que o termo "liberal" não tem nos Estados Unidos o mesmo significado que tem no Brasil. Nesse sentido afirma RAWLS (2000a, p. 5) que:

O termo liberal não tem nos Estados Unidos a mesma acepção que lhe é atribuída entre nós e na Europa. Os conservadores norte-americanos entendem-no como ${ }^{3}$ Uma breve biografia de John Rawls. Disponível em: <https://grupoeticaejustica.wordpress.com/textos/uma-breve-biografia-de-john-rawls/>.
Acesso em 18/04/2017. 
sinônimo de socialista, o que tampouco faz sentido no Brasil. [...] O liberal americano pode, pois, ser qualificado de social-democrata.

Também são nesse sentido as palavras de MÖLLER (2006, p. 18):

\begin{abstract}
A doutrina política do liberalismo norte-americano pode ser equiparada à doutrina do que entendemos como social-democracia, uma vez que, atendo-se aos limites impostos pelo sistema democrático, visa, basicamente, à adoção de mecanismos oficiais destinados a promover a elevação dos padrões de vida dos cidadãos que estão em piores condições na sociedade.
\end{abstract}

Com efeito, justifica John Rawls que se uma ação pode maximizar os benefícios, a desigualdade pode ser justificada quando beneficiar os menos favorecidos, ou seja, uma injustiça até poderá ser tolerada quando for necessária para evitar uma injustiça ainda maior.

\title{
2 CONCEPÇÃO DE JUSTIÇA RAWLSIANA
}

O problema em conceber o conceito daquilo que seria justo ou injusto esbarra na dificuldade imposta pela pluralidade de indivíduos e de doutrinas abrangentes que existem, dentre elas as doutrinas religiosas, morais e filosóficas.

Dessa maneira, encontrar uma base comum de justificação do justo, com endosso de uma pluralidade de doutrinas, foi o desafio enfrentado por John Rawls.

Sobre o tema, MÖLLER (2006, p. 18) ensina que o filósofo norte-americano, ao ambicionar encontrar uma base comum de justificação do justo, com fundamento em uma visão política liberal, parte de uma "noção da própria cultura pública como fundo comum de ideias e princípios básicos implicitamente reconhecidos",

[...] e elabora uma concepção política de justiça que pluralidade de doutrinas razoáveis possa endossar, por isso, adequada para um regime democrático constitucional, a qual designou como teoria da justiça como equidade (justice as fairness), onde o termo fairness denota o objetivo de manter-se uma condição de equidade sinônima de imparcialidade na emissão ou produção de juízos, razão pela qual poderíamos traduzir a expressão inglesa também como teoria da justiça como imparcialidade.

Nessa perspectiva, a concepção da justiça como a primeira virtude das instituições sociais é a base do pensamento de RAWLS (2000b, p. 3), equiparando-a a verdade dos sistemas de pensamento:

Rev. de Teorias da Justiça, da Decisão e da Argumentação Jurídica| e-ISSN: 2525-9849| Maranhão | v. 3 | n. 2 | p. 53 - 68 | Jul/Dez. 2017. 
A justiça é a primeira virtude das instituições sociais, como a verdade o é dos sistemas de pensamento. Embora elegante e econômica, uma teoria deve ser rejeitada ou revisada se não é verdadeira; da mesma forma leis e instituições, por mais eficientes e bem organizadas que sejam, devem ser reformadas ou abolidas se são injustas. Cada pessoa possui uma inviolabilidade fundada na justiça que nem mesmo o bem-estar da sociedade como um todo pode ignorar.

Ademais, afirma RAWLS (2000b, p. 7-8), que o objeto primário da justiça é a "estrutura básica da sociedade, ou mais exatamente, a maneira pela qual as instituições sociais mais importantes distribuem direitos e deveres fundamentais e determinam a divisão de vantagens provenientes de cooperação social".

Nesse viés, para que um sistema democrático seja sólido, necessário se faz que exista uma base pública de justificação, ou seja, um consenso sobre determinadas questões.

Referido consenso é o chamado consenso sobreposto, que poderia ser conceituado como(RODRIGUES JUNIOR, 2012):

[...] um mecanismo de justificação das instituições políticas e jurídicas, fazendo com que a sociedade adote uma pauta mínima de valores, cuja adesão seja a mais ampla entre seus diversos segmentos, independentemente do credo religioso, da orientação político-ideológica ou da filosofia de seus integrantes.

Nessa perspectiva, RAWLS (2000b, p. 4) faz duas afirmações e as considera como verdadeiras.

A primeira consiste em dizer que a sociedade é "uma associação mais ou menos autossuficiente de pessoas que em suas relações mútuas reconhecem certas regras de conduta como obrigatórias" e que, na maioria das vezes, essas pessoas agem de acordo com essas regras.

A segunda consiste em supor que "essas regras especifiquem um sistema de cooperação concebido para promover o bem dos que fazem parte dela".

Apesar de concordarmos com a primeira afirmação, ousamos discordar da segunda. E nos explicamos. Ocorre que as regras alhures até podem especificar ou sistema cooperação, mas que, a nosso ver, não foi concebido para promover o bem dos que fazem parte dela, mas sim, para promover o bem de setores específicos dessa sociedade.

Mas aqui não repousa propriamente uma crítica à teoria de Rawls. Isso porque, apesar de ter sido expresso na afirmação de que as regras especificam um sistema de cooperação concebido para promover o bem de todos os que fazem parte dela, ele também afirma que “embora uma sociedade seja um empreendimento cooperativo visando vantagens mútuas, ela é 
tipicamente marcada por um conflito bem como por uma identidade de interesses". (RAWLS, 2000b, p. 4).

Outro apoio da argumentação de Rawls está no desenvolvimento do conceito de posição original. Com efeito, afirma Rawls, que a posição original é um estado inicial apropriado para assegurar a equivalência dos consensos básicos nele estabelecidos (RAWLS, 2000b, p. 19).

Em outras palavras, isso quer significar que tem-se que, hipoteticamente, tirar os indivíduos das posições sociais em que se encontram e transferi-los para uma posição originária, onde ele estará coberto por um véu da ignorância.

São firmes nesse propósito as palavras de RAWLS (2000b, p. 19):

\begin{abstract}
Os princípios da justiça são escolhidos sob um véu de ignorância. Isso garante que ninguém é favorecido ou desfavorecido na escolha dos princípios pelo resultado do acaso natural ou pela contingência de circunstâncias sociais. Uma vez que todos estão numa situação semelhante e ninguém pode designar princípios para favorecer sua condição particular, os princípios da justiça são o resultado de um consenso ou ajuste equitativo. Pois dadas as circunstâncias da posição original, a simetria das relações mútuas, essa situação original é equitativa entre os indivíduos tomados como pessoas éticas, isto é, como seres racionais com objetivos próprios e capaz, na minha hipótese, de um senso de justiça. A posição original é, poderíamos dizer, o status quo inicial apropriado, e assim os consensos fundamentais nela alcançados são equitativos. Isso explica a propriedade da frase "justiça como equidade": ela transmite a ideia de que os princípios de justiça são acordados numa situação inicial que é equitativa.
\end{abstract}

Assim, ao se fazer esta transferência, esse indivíduo não vai saber qual a posição social que ocupa; não saberá se é homem ou mulher; rico ou pobre; adulto ou criança; branco ou negro, etc.

Destarte, sob o véu da ignorância, as partes "não sabem como as várias alternativas irão afetar o seu caso particular, e são obrigadas a avaliar os princípios unicamente com base nas considerações gerais" (RAWLS, 2000b, p. 147).

Nesse viés, o conceito de posição original do modo como é utilizado por John Rawls, "é o que apresenta, do ponto de vista filosófico, a interpretação mais adequada dessa situação de escolha inicial para os propósitos de uma teoria da justiça” (RAWLS, 2000b, p. 20).

Dessa forma, sob o véu da ignorância os indivíduos conseguirão formular regras imparciais, justas e universais para estabelecer um conceito de justiça equitativa.

Por fim, para que uma sociedade seja regulada e ordenada, é exigido um conjunto de princípios para determinar a divisão das vantagens sociais.

Rev. de Teorias da Justiça, da Decisão e da Argumentação Jurídica| e-ISSN: 2525-9849| Maranhão | v. 3 | n. 2 | p. 53 - 68 | 
Esses princípios (que também fundamentam a argumentação de Rawls) são os princípios da justiça social, que "fornecem um modo de atribuir direitos e deveres nas instituições básicas da sociedade e definem a distribuição apropriada dos benefícios e encargos da cooperação social”. (RAWLS, 2000b, p. 5).

Doravante, analisar-se-áos referidos princípios da justiça social.

\section{PRINCÍPIOS DA JUSTIÇA SOCIAL}

A pergunta que John Rawls fez a si próprio foi: na posição original (sob o véu da ignorância), os utilitaristas (que defendem a maior felicidade para o maior número de pessoas) escolheriam continuar defendendo isso quando instados a se manifestar sobre suas vidas coletivas? E John Rawls, em reação ao utilitarismo, responde a indagação: NÃO, eles não defenderiam a maior felicidade para o maior número de pessoas se estivessem na posição original e sob o véu da ignorância.

O fundamento para essa negativa consiste no fato de que se o véu da ignorância começar a ser levantado e a vida real começar, todos querem ser respeitados e tratados dignamente. Após levantar o véu, o utilitarista que descobre ser parte de uma minoria não vai admitir ser oprimido e sofrer um tratamento desumano em nome da maior felicidade para o maior número de pessoas.

Dessa maneira, em reação ao utilitarismo, RAWLS (2000b, p. 19) argumenta em sua obra que os princípios da justiça estão fundados em um contrato hipotético, devendo a realização desse contrato hipotético, ocorrer numa posição original de igualdade. Observar-seá suas palavras nesse sentido:

Na justiça como equidade a posição original de igualdade corresponde ao estado de
natureza na teoria tradicional do contrato social. Essa posição original não é,
obviamente, concebida como uma situação histórica real, muito menos como uma
condição primitiva da cultura. É entendida como uma situação puramente hipotética
caracterizada de modo a conduzir a uma certa concepção de justiça. Entre as
características essenciais dessa situação está o fato de que ninguém conhece seu lugar
na sociedade, a posição de sua classe ou o status social e ninguém conhece sua sorte
na distribuição de dotes e habilidades naturais, sua inteligência, força, e coisas
semelhantes. Eu até presumirei que as partes não conhecem suas concep̧̧̃̃es do bem
ou suas propensões psicológicas particulares. 
Nesse viés, ele apresenta dois princípios de justiça sobre os quais acredita que haja um consenso na posição original. Em sua explanação inicial, apresenta referidos princípios da seguinte maneira:

Primeiro: cada pessoa deve ter um direito igual ao mais abrangente sistema de liberdades básicas iguais que seja compatível com um sistema semelhante de liberdades para as outras.

Segundo: as desigualdades sociais e econômicas devem ser ordenadas de tal modo que sejam ao mesmo tempo (a) consideradas como vantajosas para todos dentro dos limites do razoável, e (b) vinculadas a posições e cargos acessíveis a todos. (RAWLS, 2000b, p. 64).

Com efeito, afirma ainda referido autor, que esses princípios "se aplicam primeiramente à estrutura básica da sociedade, governam a atribuição de direitos e deveres e regulam as vantagens econômicas e sociais". (RAWLS, 2000b, p. 64).

Em outras palavras, o primeiro princípio (da liberdade igual) consiste em estabelecer igual liberdade para todos, devendo essa liberdade ser usufruída ao máximo.

Nesse aspecto, Rawls lista quais seriam essas liberdades:

\begin{abstract}
É essencial observar que é possível determinar uma lista dessas liberdades. As mais importantes entre elas são a liberdade política (o direito de votar e ocupar um cargo público) e a liberdade de expressão e reunião; a liberdade de consciência e de pensamento; as liberdades da pessoa, que incluem a proteção contra a opressão psicológica e a agressão física (integridade da pessoa); o direito à propriedade privada e a proteção contra a prisão e a detenção arbitrárias, de acordo com o conceito de estado de direito. Segundo o primeiro princípio, essas liberdades devem ser iguais. (RAWLS, 2000b, p. 65)
\end{abstract}

Trata-se de uma liberdade destinada a assegurar o exercício dos direitos civis e políticos, ou seja, os direitos de primeira geração, que não poderiam ser trocados por vantagens econômicas.

Já o segundo princípio estabelece que as desigualdades econômicas e sociais serão consideradas legítimas, desde que seja observado o princípio da diferença e o princípio da oportunidade justa.

São nesse sentido as palavras de Rawls:

[...] o segundo princípio se aplica à distribuição de renda e riqueza e ao escopo das organizações que fazem uso de diferenças de autoridade e de responsabilidade. Apesar de a distribuição de riqueza e renda não precisar ser igual, ela deve ser vantajosa para todos e, ao mesmo tempo, as posições de autoridade e responsabilidade devem ser acessíveis a todos. (RAWLS, 2000b, p. 65). 
Nesse contexto, VAZ (2006, p. 1) conceitua os princípios da diferença e da oportunidade justa da seguinte maneira:

\begin{abstract}
Princípio da diferença: A sociedade deve promover a distribuição igual da riqueza, excepto se a existência de desigualdades económicas e sociais gerar o maior benefício para os menos favorecidos.

Princípio da oportunidade justa: As desigualdades económicas e sociais devem estar ligadas a postos e posições acessíveis a todos em condições de justa igualdade de oportunidades.
\end{abstract}

Agora fala-se em direitos sociais, ou seja, em direitos de segunda geração, dentre eles saúde, educação, lazer, etc.

O princípio da diferença é um princípio de igualdade que tem um plus, uma qualificação: apenas as desigualdades sociais e econômicas que contribuam para o benefício dos menos favorecidos serão permitidas.

Há, como visto, uma condicionante para que seja admitida a desigualdade de rendimentos e riqueza, qual seja, que as diferenças sejam contributivas para o benefício de todos, mas especialmente aos menos favorecidos.

A título ilustrativo, é justo que os Ministros do Supremo Tribunal Federal ganhem R\$ $37.000,00$ se os impostos pagos por eles entrassem no sistema de maneira que os menos favorecidos fossem beneficiados, juntamente com os Ministros.

Isso seria aceito sob o véu da ignorância, pois na posição original jogar-se-ia pelo seguro e ainda ter-se-ia a vantagem da obtenção dosbenefícios caso não fossem os possuidores da maior riqueza e rendimentos.

De outro lado, para que se entenda o princípio da justa oportunidade, deve-se entender as teorias de justiça distributiva existentes, que devem explicar como o rendimento, a riqueza, as oportunidades e as coisas boas da vida devem ser distribuídas.

Uma das teorias da justiça distributiva, baseada num sistema libertário, afirma que é justo um sistema de distribuição, de trocas livres, de economia de mercado livre, havendo uma ideia de igualdade formal, onde os empregos e as carreiras devem estar à disposição de todos, ou seja, todos podem competir, pois as carreiras estão abertas aos talentos.

A crítica feita a esse sistema consiste no fato de que se os empregos estão postos em igualdade formal a todos, os que nasceram em famílias de melhor posição social vão poder se 
preparar melhor do ponto de vista educacional em busca desses empregos, não sendo o acaso do nascimento uma base justa.

A segunda teoria da justiça distributiva se baseia na meritocracia, ou seja, um sistema meritocrático, onde todos terão igualdade de oportunidades. Entretanto, mesmo que todos saiam do mesmo ponto de partida, os que chegarão na frente serão os mais bem preparados, não sendo também a igualdade de oportunidades inicial uma base justa.

Por fim, a teoria de justiça distributiva defendida por Rawls é uma concepção mais igualitária, ou seja, um sistema igualitário. Seu fundamento não está inclinado ao total nivelamento igualitário.

De início ele quer um nivelamento igualitário, mas esse sistema defendido por Rawls admite que pessoas possam se beneficiar de seus talentos e da sorte de ter nascido em uma família rica que lhe proporciona um melhor preparo educacional, desde que isso contribua para beneficiar os menos favorecidos.

Aqui cabe outra ilustração. É justo que um médico ganhe mais dinheiro do que a média dos trabalhadores, desde que, ele utilize esse dinheiro a mais para si e também para fazer cursos em busca do desenvolvimento da medicina que vai, ao final, beneficiar os menos favorecidos que poderão ter a seu dispor vacinas, tratamentos de saúde mais desenvolvidos, etc.

Deveras, o resumo da explanação feita por Rawls consiste na afirmação de que as desigualdades sociais e econômicas serão consideras legítimas quando observados os princípios da diferença e da justa oportunidade.

Necessário frisar nesse ponto que existe uma ordem de prioridade dos princípios basilares da teoria de Rawls:

Esses princípios devem obedecer a uma ordenação social, o primeiro antecedendo o segundo. Essa ordenação significa que as violações das liberdades básicas iguais protegidas pelo primeiro princípio não podem ser justificadas nem compensadas por maiores vantagens econômicas e sociais. Essas liberdades têm um âmbito central de aplicação dentro do qual elas só podem ser limitadas ou comprometidas quando entram em conflito com outras liberdades básicas. (RAWLS, 2000b, p. 65).

São também nesse sentido as palavras de VAZ (2006, p. 1):

Estes três princípios formam a concepção de justiça de Rawls. Mas por si só estes princípios não resolvem conflitos como os que viste. Se queres ter uma espécie de guia nas tuas escolhas, é preciso ainda estabelecer uma ordem de prioridades entre os princípios. Assim, o princípio da liberdade igual tem prioridade sobre os outros dois e o princípio da oportunidade justa tem prioridade sobre o princípio da diferença.

Rev. de Teorias da Justiça, da Decisão e da Argumentação Jurídica| e-ISSN: 2525-9849| Maranhão | v. 3 | n. 2 | p. 53 - 68 | Jul/Dez. 2017. 
Apenas para fins ilustrativos, não se pode abdicar da liberdade de expressão para não pagar impostos. Da mesma maneira que a liberdade de religião é um direito que não pode ser violado por questões econômicas. Entretanto, poderá haver limitação quando a liberdade de expressão colidir com a liberdade de religião, porque ambas são consideradas liberdades básicas.

Como as liberdades básicas têm prioridade absoluta em relação aos demais princípios, pode-se considerar John Rawls um liberal.

Porém, um liberal com preocupações igualitárias, pois Rawls admite a desigualdade de oportunidades ou rendimentos para beneficiar os menos favorecidos. Em outras palavras, se uma ação pode maximizar benefícios para os menos favorecidos, a desigualdade é legítima, justificada.

Seguem as palavras de John Rawls sobre a justificação da desigualdade:

Todos os valores sociais - liberdade e oportunidade, renda e riqueza, e as bases sociais da autoestima - devem ser distribuídos igualitariamente a não ser que uma distribuição desigual de um ou de todos esses valores traga vantagens para todos. (RAWLS, 2000b, p. 66).

Isso vai ao encontro das ponderações feitas por CRUZ (2013, p. 1):

\begin{abstract}
A partir disso Rawls trabalha com a ideia da diferença de uma forma diferente: as desigualdades devem ser preservadas e não extintas desde que ordenadas de forma a trazer benefícios principalmente aos menos favorecidos. Essa sua teoria trabalha os princípios de justiça para que eles sejam válidos para todos e beneficiem todos pelo efeito da ação cooperativa geral dos grupos componentes da sociedade.
\end{abstract}

Em suma, Rawls admite e preserva as desigualdades, mas impõe uma condicionante de justiça, que consiste no fato de que essas desigualdades devem beneficiar os menos favorecidos para que sejam consideradas justas.

\title{
3.1 ARGUMENTOS A FAVOR DO PRINCÍPIO DA DIFERENÇA
}

São dois os argumentos favoráveis ao princípio da diferença: a) argumento intuitivo da igualdade de oportunidades; e b) argumento do contrato social hipotético. 
O primeiro argumento (intuitivo da igualdade de oportunidades) consiste na afirmação de que não são as circunstâncias que devem determinar o destino das pessoas, mas sim as suas próprias escolhas.

São nesse sentido as palavras de VAZ (2006, p. 1), quando afirma que "ninguém merece ver as suas escolhas e ambições negadas pela circunstância de pertencer a uma certa classe social ou raça."

Para ilustração, intuitivamente não acha-se plausível que negros não possam exercer cargos de chefia pelo simples fato de serem negros. Esse exemplo serve também para classe social, origem, etc.

Já no segundo argumento (do contrato social hipotético), a situação hipotética da posição original é considerada uma situação equitativa.

Dessa maneira num comparativo de dois mundos, sendo um deles mais rico (Mundo 1: com 98 e 3 bens primários para dividir), e outro mais pobre (Mundo 2: com 65 e 5 bens primários para dividir), o indivíduo colocado hipoteticamente na posição original e sob o véu da ignorância, racionalmente escolherá a divisão dos bens do Mundo 2, porque nele a pessoa menos favorecida fica melhor em termos de distribuição dos bens primários.

Assim, pode-se afirmar que Rawls aplica a regra maximin, dado que procura maximizar o mínimo: "A regra maximin determina que sejam classificadas as alternativas em vista de seu pior resultado possível: deve-se adotar a alternativa cujo pior resultado seja superior aos piores resultados das outras". (RAWLS, 2000b, p. 165).

É clarividente que a utilidade média no mundo mais rico é maior $(6,66)$. Entretanto, como está o indivíduo coberto pelo véu da ignorância é mais racional que a escolha recaia sobre a distribuição dos bens primários no Mundo 2, apesar de ter uma utilidade média menor $(5,33)$.

\section{CRÍTICAS À TEORIA DE RAWLS}

Como alertado no resumo deste trabalho, John Rawls assumiu que não pôde lidar com todas as críticas recebidas, estando plenamente consciente das falhas que ainda persistem em sua teoria (RAWLS, 2000b, p. XXVI).

Contudo, antes do aprofundamento nas críticas da teoria, é necessário o entendimento da conceituação do que são bens primários na teoria de Rawls para melhor entendimento de referidas críticas: 
Os bens primários, como já observei, são coisas que se supõe que um homem racional deseja, não importa o que mais ele deseje. Independentemente de quais sejam em detalhes os planos racionais de um indivíduo, supõe-se que há várias coisas das quais ele preferiria ter mais a ter menos. (RAWLS, 2000b, p. 97).

Com efeito, Ralws conceitua os bens primários sociais como sendo "direitos, liberdades e oportunidades, assim como renda e riqueza". (RAWLS, 2000b, p. 98). São então aqueles bens diretamente distribuídos pelas instituições sociais.

Já os bens primários naturais são os bens que NÃO são diretamente distribuídos pelas instituições sociais, apesar de serem influenciados por ela. São exemplos desses bens, a saúde, a inteligência e os talentos naturais.

Sobre a diferença entre os tipos de bens primários, são notáveis os ensinamentos de VAZ (2006, p. 1):

Há dois tipos de bens primários, os sociais e os naturais. Os bens primários sociais são directamente distribuídos pelas instituições sociais e incluem o rendimento e a riqueza, as oportunidades e os poderes, e os direitos e as liberdades. Os bens primários naturais são influenciados, mas não directamente distribuídos, pelas instituições sociais e incluem a saúde, a inteligência, o vigor, a imaginação e os talentos naturais.

Feita a conceituação do que são os bens primários e seus tipos, adentrar-se-á na análise das críticas propriamente ditas.

A primeira crítica que se faz está no fato de que a teoria de Rawls não compensa as desigualdades naturais. Dessa maneira, mesmo que haja igualdade de oportunidades os mais talentosos e saudáveis vão, como regra, se sobressair e ter rendimentos maiores.

Assim, mesmo que se aplique o princípio da diferença para dizer que os mais talentosos e saudáveis poderão se sobressair e ter rendimentos maiores desde que com isso beneficiem os menos favorecidos (aqueles que têm menos bens sociais primários), isso não resolve a colisão entre o primeiro argumento do princípio da diferença, chamado argumento intuitivo da igualdade de oportunidades, que prevê o destino das pessoas deve depender de suas próprias escolhas.

Segue um exemplo para melhor ilustrar essa colisão. Dois irmãos gêmeos em uma posição de igualdade, com as mesmas liberdades, riquezas e oportunidades. Um desses irmãos é acometido por um câncer que o torna incapacitante para o trabalho. 
Com fundamento na teoria de Rawls, esse irmão doente não é considerado menos favorecido, porque só conseguimos chegar ao conceito de quem seja menos favorecido quando levamos em consideração os bens sociais primários (direitos, liberdades e oportunidades, assim como renda e riqueza).

Em outras palavras, o destino do irmão doente não dependeu de sua própria escolha, mas sim da circunstância em que por acaso se encontra. Isso é justamente o contrário do primeiro argumento favorável ao princípio da diferença (argumento intuitivo da igualdade de oportunidades).

A segunda crítica que se faz reside na circunstância de que certas escolhas subsistem injustamente a outras, fazendo com que sejam compensados os custos escolhidos.

E a explicação será com base em outro exemplo.

Dois funcionários de uma fábrica de automóveis que comungam os mesmos direitos, liberdades, oportunidades, ganham o mesmo salário e tem o mesmo patrimônio financeiro. Um deles é torcedor do time "A" e outro torcedor do time "B".

O que é torcedor do time "A”, em razão de seu fanatismo, gasta todo seu salário com camisas do clube, viagens para acompanhar o time e ingressos para jogos.

Já o torcedor do time "B", em razão de seu time estar numa péssima fase, resolve fazer um curso técnico profissionalizante às terças e sextas-feiras à noite (dias e horários dos jogos do time "B"). Com seu aprendizado no curso profissionalizante, passa a fazer pequenos serviços em produtos eletrônicos nos finais de semana e com isso aumenta significativamente sua renda. O torcedor do time "A", como gastou todo seu salário com o clube do coração, necessitará do apoio do Estado para conseguir ter seus direitos de segunda geração (sociais) assegurados.

Com efeito, se aplicamos o princípio da diferença nesse caso, o eletricista esforçado, torcedor do time "B", irá custear a escolha que fez e ainda subsidiar a escolha do torcedor fanático do time "A", através dos maiores impostos que pagará, havendo então a destruição da igualdade ao invés de sua promoção.

A terceira crítica consiste no fato de que Rawls não falou sobre a prioridade do princípio da justa oportunidade sobre o princípio da diferença, pois tratou esses dois princípios como se fossem um único princípio.

Entretanto, deve ser estabelecida uma prioridade entre esses dois princípios, pois deve preponderar a oportunidade justa sobre o princípio da diferença no sentido de que o indivíduo não pode abdicar de ter uma "oportunidade justa" sob o argumento de que ao final (no ajuste

Rev. de Teorias da Justiça, da Decisão e da Argumentação Jurídica| e-ISSN: 2525-9849| Maranhão | v. 3 | n. 2 | p. 53 - 68 | 
de contas social), em sendo considerado menos favorecido, seria ele beneficiado, pois o princípio da diferença estabelece exatamente isso: admissão da desigualdade de rendimentos e riqueza, desde que as diferenças sejam contributivas para o benefício de todos, mas especialmente aos menos favorecidos.

Segue mais um exemplo esclarecedor.

Para dois adolescentes em idade laboral são oferecidos empregos em uma fábrica. Um deles prontamente aceita. $\mathrm{O}$ outro não aceita o emprego, porque sabe que se não aceitar, ao final (no ajuste de contas social), ele será considerado menos favorecido e será beneficiado. haverá então no caso de não estabelecimento da prioridade principiológica aqui defendida, subsídio da escolha do que não aceitou o emprego através dos maiores impostos que pagará o trabalhador, podendo haver a destruição da igualdade ao invés de sua promoção.

Por fim, a quarta crítica consiste em um pecado cometido por John Rawls, pois referido autor se considera um crítico ao utilitarismo, mas na verdade, referido filósofo é um utilitarista porque defende a desigualdade quando ela seja benéfica a todos, principalmente para os menos favorecidos, ou seja, uma felicidade para o maior número de pessoas da sociedade. O que seria isso senão o utilitarismo?

Analisadas as críticas à brilhante (mas ainda imperfeita) teoria, passamos às conclusões.

\section{CONSIDERAÇÕES FINAIS}

À guisa de conclusões, percebeu-se durante a exposição do presente trabalho, que o problema em conceber a definição daquilo que seria justo ou injusto esbarra na dificuldade imposta pela pluralidade de indivíduos e de doutrinas abrangentes que existem, dentre elas as doutrinas religiosas, morais e filosóficas.

Nesse sentido, John Bordley Rawls desenvolveu uma teoria da justiça fundamentada em princípios com a finalidade de encontrar uma base comum de justificação do justo, com endosso de uma pluralidade de doutrinas.

Com uma noção claramente liberal, mas com preocupações igualitárias, John Rawls procurou argumentar em favor da escolha de um mundo mais igualitário porque nesse mundo a pessoa menos favorecida - consideradaaquele que tem menos bens sociais primários ficamelhor em termos de distribuição desses mesmos bens. 
Em outras palavras, a teoria de justiça distributiva defendida por Rawls é uma concepção mais igualitária, ou seja, um sistema igualitário, cujo fundamento não está inclinado ao total nivelamento igualitário.

Apesar de se buscar um inicial nivelamento igualitário, o sistema defendido por Rawls admite que pessoas possam se beneficiar de seus talentos e da sorte de ter nascido em uma família rica que lhe proporciona um melhor preparo educacional, desde que isso contribua para beneficiar os menos favorecidos.

Rawls apoiou os fundamentos de sua argumentação no consenso sobreposto, na posição original e nos princípios de justiça, justamente com a finalidade de trabalhar a ideia da diferença de uma forma diferente, preservando as desigualdades (e não extinguindo-as) desde que ordenadas de forma a trazer benefícios principalmente aos menos favorecidos.

Entretanto, ainda persistem falhas na brilhante teoria desenvolvida por Rawls, sendo justas as críticas em relação à falha da teoria em não compensar as desigualdades naturais, bem como em relação à afirmação de que certas escolhas subsidiam injustamente outras escolhas, fazendo com que sejam compensados os custos escolhidos.

Por fim, identifica-se um grande pecado cometido por John Rawls, que fundamenta sua teoria como uma crítica ao utilitarismo. Entretanto, referido filósofo possui traços da corrente utilitarista ao defender a desigualdade quando benéfica a todos, principalmente para os menos favorecidos.

\section{BIBLIOGRAFIA ESPECÍFICA E GERAL}

CRUZ, Daniel Nery da.Uma reflexão sobre a teoria de justiça em John Rawls. Disponível em: $\langle$ http://www.theoria.com.br/edicao12/uma_reflexao_sobre_a_teoria_de_justica_daniel.pdf $\rangle$. Acesso em 07/08/2017.

MÖLLER, Josué Emilio. A justiça como equidade em John Rawls. Porto Alegre: Sergio Antonio Fabris Editor, 2006.

RAWLS, John. O liberalismo político. $2^{\text {a }}$ ed. São Paulo: Ática, 2000a. Uma teoria da justiça. São Paulo: Martins Forense, 2000b.

RODRIGUES JUNIOR, Otavio Luiz. “Consensos sobrepostos” e decisões judiciais. 2012. Disponível em: <http://www.conjur.com.br/2012-set-26/direito-comparado-consensossobrepostos-decisoes-judiciais >. Acesso em 01/08/2017. 
VAZ, Faustino. Crítica a teoria da justiça de John Rawls. Disponível em: <http://criticanarede.com/pol_justica.html>. Acesso em 15/08/2017. 